University of Nebraska - Lincoln

DigitalCommons@University of Nebraska - Lincoln

Faculty Publications from the Harold W. Manter Laboratory of Parasitology

$6-1-2000$

Phylogeny of the Species of the Genus Litomosoides

(Nematatoda: Onchocercidae): Evidence of Rampant Host

Switching

Sara V. Brant

University of New Mexico, sbrant@unm.edu

Scott Lyell Gardner

University of Nebraska - Lincoln, slg@unl.edu

Follow this and additional works at: https://digitalcommons.unl.edu/parasitologyfacpubs

Part of the Parasitology Commons

Brant, Sara V. and Gardner, Scott Lyell, "Phylogeny of the Species of the Genus Litomosoides

(Nematatoda: Onchocercidae): Evidence of Rampant Host Switching" (2000). Faculty Publications from the Harold W. Manter Laboratory of Parasitology. 43.

https://digitalcommons.unl.edu/parasitologyfacpubs/43

This Article is brought to you for free and open access by the Parasitology, Harold W. Manter Laboratory of at DigitalCommons@University of Nebraska - Lincoln. It has been accepted for inclusion in Faculty Publications from the Harold W. Manter Laboratory of Parasitology by an authorized administrator of DigitalCommons@University of Nebraska - Lincoln. 


\title{
PHYLOGENY OF SPECIES OF THE GENUS LITOMOSOIDES (NEMATATODA: ONCHOCERCIDAE): EVIDENCE OF RAMPANT HOST SWITCHING
}

\author{
Sara V. Brant ${ }^{\star}$ and Scott L. Gardner \\ Harold W. Manter Laboratory of Parasitology, W-529 Nebraska Hall, University of Nebraska-Lincoln, Lincoln, Nebraska 68588-0514
}

\begin{abstract}
Filarioid nematodes of the genus Litomosoides occur in the abdominal and (or) thoracic cavities of marsupials, rodents, and bats of the Nearctic and Neotropical regions. In this study, the phylogenetic relationships among these nematodes were estimated with a parsimony analysis of morphological characters derived from species descriptions. This nonweighted analysis produced 20 shortest trees. The monophyly of the genus was not supported in that Litomosoides thomomydis and Litomosoides westi failed to group with the other members of the genus. When these 2 taxa (parasites of pocket gophers) were excluded, monophyly of Litomosoides was supported by 2 synapomorphies (structure of the walls and general shape of the stoma); however, ancestor-descendant relationships among the species in the genus were not well resolved. A posteriori reweighting of the characters produced a single tree, different from all 20 most parsimonious trees. Alternative host-parasite evolutionary models were tested against these results supporting the process of host switching as being most important in forming the patterns of mammal-nematode associations that have been detected in this group of nematodes.
\end{abstract}

Examining the patterns of occurrences of various kinds of parasites in hosts based on well corroborated phylogenies can lead to the investigation of questions that may be of interest to students of zoogeography, coevolution, and biological diversity (Brooks and McLennan, 1993). Phylogenetic trees derived separately of hosts and their parasites can be compared to one another, and this comparison can provide information on the extent of coevolution between parasites and their hosts (Brooks, 1985; Brooks and McLennan, 1993; Huelsenbeck and Rannala, 1997).

Species of Litomosoides Chandler, 1931 are filarioid nematodes in the family Onchocercidae occupying the thoracic and abdominal cavities of a wide range of small mammals. The range of mammalian hosts presently includes species representing 4 families of bats, 5 families of rodents, and 1 family of marsupial. These nematodes are reported exclusively from mammals in the Nearctic and Neotropical regions with most species occurring in mammals of South America. Each species of Litomosoides appears to be specific to 1 of 3 mammalian orders in that a species found in bats does not occur in marsupials or rodents (Table I). These nematodes have a wide distribution throughout the Neotropical and southern Nearctic regions and several species have been well studied from both experimental and morphological perspectives. As such, these nematodes offer an ideal model for continuing investigations into their history as parasites of New World mammals. The distribution of these nematodes through such a wide range of taxonomically distantly related mammals provides an opportunity to examine host-parasite associations from a phylogenetic perspective.

Filarioid nematodes of the genus Litomosoides usually are considered to have a reduced set of cephalic characters and cuticular ornamentation relative to corresponding characters found in free-living nematodes. These reductions are believed to be the result of adaptation to life within host tissue (Chitwood and Chitwood, 1974; Bain, 1981; Chabaud and Bain, 1994). Alternatively, these reductions could be a result of developmental constraints, an historical accident, or both (Brooks

Received 16 September 1998; revised 9 December 1998 and 12 October 1999; accepted 12 October 1999.

* Present address: School of Biological Sciences, University of Nebraska-Lincoln, 348 Manter Hall, Lincoln, Nebraska 68588-0118. and McLennan, 1991). For example, the ancestor of the filarioid nematodes had reduced external cuticular ornamentation, so all of its descendants do also. This perceived paucity of morphological characters has hindered the development of phylogenetic hypotheses of the group (Chabaud and Bain, 1994), and up to this time no cladistic study has been performed among species of Litomosoides. Bain et al. $(1989,1991)$ posited that the ancestral hosts for members of the genus Litomosoides were microchiropteran bats of Central and South America and that as recently as 5 million years ago (mya), these parasites diversified via host switching into muroid rodents and marsupials. Interestingly, no hypothesis proposes an early origin in marsupials.

Understanding the difference between a host-parasite relationship that is produced as the result of a long-term historical association and one that exists due to an ecological event such as a host switch depends on the development and comparison of robust phylogenetic hypotheses for both the hosts and their parasites (Brooks, 1985). Complete phylogenetic tracking of a host lineage by a lineage of parasites is a clear example of cospeciation (Brooks and McLennan, 1993). The occurrence of sister taxa of parasites in hosts that are not sister taxa may be an example of host switching (Brooks, 1985; Brooks and McLennan, 1993).

Bain et al. (1989, 1991) proposed that host-switching events have been the primary mode of evolutionary diversification in Litomosoides (Fig. 1A). Alternatively, given that these nematodes are host specific, each to 1 of 3 mammalian orders (Rodentia, Chiroptera, or Marsupialia), it is possible that species of Litomosoides coevolved/cospeciated in synchrony with their host (Fig. 1B). The basic null hypothesis of this study is to assume complete cospeciation with their hosts. Any evidence of deviation would indicate host-switching phenomena.

Herein, we present a hypothesis of the phylogenetic relationships among species of the genus Litomosoides based on a cladistic analysis of morphological characters. We address the following questions: Do species of the genus Litomosoides form a monophyletic group? If the answer is yes, we ask what are the hosts of the taxa that occur at the base of the parasite tree? And, are there clades of Litomosoides that occur exclusively in bats, rodents, or marsupials. The trees that we constructed were based mostly on characters and features used commonly for species-level diagnoses. 
TABLE I. List of all the described species of Litomosoides with the host species and geographic distributions.

\begin{tabular}{|c|c|c|}
\hline & Order Chiroptera (bats) & \\
\hline Litomosoides sp. & Artibeus jamaicensis & M \\
\hline \multirow[t]{3}{*}{ Litomosoides braziliensis $\dagger$} & Carollia perspicillata & $\mathrm{Bo}, \mathrm{Br}, \mathrm{C}, \mathrm{CR}, \mathrm{M}, \mathrm{V}$ \\
\hline & Carollia brevicauda & Bo \\
\hline & Phyllostomus sp. & $\mathrm{V}$ \\
\hline Litomosoides caliensis & Sturnira lilium & $\mathrm{C}$ \\
\hline \multirow{5}{*}{ Litomosoides chandleri $\dagger$} & A. jamaicensis & $\mathrm{Br}, \mathrm{C}$ \\
\hline & Sturnira lilium & Bo \\
\hline & Sturnira oporaphilum & Bo \\
\hline & Phyllonycteris poeyi & $\mathrm{Br}$ \\
\hline & Tadarida laticaudata & $\mathrm{Br}$ \\
\hline \multirow{4}{*}{ Litomosoides guiterasi $\dagger$} & C. perspicillata & $\mathrm{Br}$ \\
\hline & Pteronotus parnelli & $\mathrm{Cb}$ \\
\hline & Eptesicus fuscus & $\mathrm{AL}, \mathrm{Cb}$ \\
\hline & Myotis lucifugus & $\mathrm{AL}$ \\
\hline Litomosoides hamletti & G. soricina & $\mathrm{Br}$ \\
\hline Litomosoides leonilavazqae & Macrotus mexicanus & $\mathbf{M}$ \\
\hline \multirow[t]{2}{*}{ Litomosoides molossi $\dagger^{\dagger}$} & Molossus molossus & $\mathrm{C}$ \\
\hline & Molossus major & $\mathrm{Br}$ \\
\hline \multirow[t]{2}{*}{ Litomosoides teshi† } & C. perspicillata & $\mathrm{C}$ \\
\hline & Order Rodentia (rodents) & \\
\hline Litomosoides anderson $\dagger^{\dagger}$ & Ctenomys opimus & Bo \\
\hline Litomosoides carinii $\dagger$ & Rattus norvegicus & $\mathrm{V}$ \\
\hline Litomosoides galizai $\dagger$ & Oecomys trinitatis & $\mathrm{Br}$ \\
\hline \multirow[t]{2}{*}{ Litomosoides hoplomyis $\dagger$} & Hoplomys gymnurus & $\mathrm{C}$ \\
\hline & Proechimys semispinosus & $\mathrm{C}$ \\
\hline Litomosoides kohnae $\dagger$ & Nectomys squamipes & $\mathrm{Br}$ \\
\hline Litomosoides legerae $\dagger$ & Oxymycterus quaestor & $\mathrm{Br}$ \\
\hline Litomosoides patersoni & Holochilus vulpinus & $\mathrm{Br}$ \\
\hline Litomosoides scotti $\uparrow$ & Oryzomys palustris & FL \\
\hline Litomosoides sigmodontis $\dagger$ & Sigmodon hispidus & $\mathrm{TX}$ \\
\hline Litomosoides silvai & Akodon cursor & $\mathrm{Br}$ \\
\hline Litomosoides thomomydis $\dagger$ & Thomomys talpoides & $\mathrm{CO}$ \\
\hline \multirow[t]{2}{*}{ Litomosoides west $i \dagger$} & Geomys bursarius & $\mathrm{CO}$ \\
\hline & Order Marsupialia & \\
\hline Litomosoides barreti $\dagger$ & Marmosa cinerea & $\mathrm{Br}$ \\
\hline Litomosoides petteri $\dagger$ & M. cinerea & $\mathrm{Br}$ \\
\hline
\end{tabular}

$* \mathrm{AL}=$ Alberta, $\mathrm{Bo}=$ Bolivia, $\mathrm{Br}=$ Brazil, $\mathrm{C}=$ Colombia $, \mathrm{Cb}=\mathrm{Cuba}, \mathrm{CO}=$ Colorado, $\mathrm{CR}=\mathrm{Costa} \mathrm{Rica}, \mathrm{FL}=\mathrm{Florida}, \mathrm{M}=\mathrm{Mexico}, \mathrm{P}=\mathrm{Panama}, \mathrm{TX}=\mathrm{Texas}$, $\mathrm{V}=$ Venezuela.

$\dagger$ Designates species used in the present cladistic analysis. 
A

B

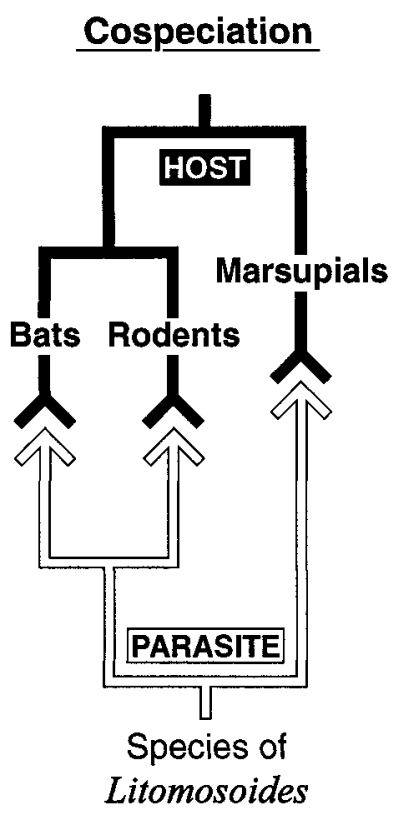

\section{Host-switching}
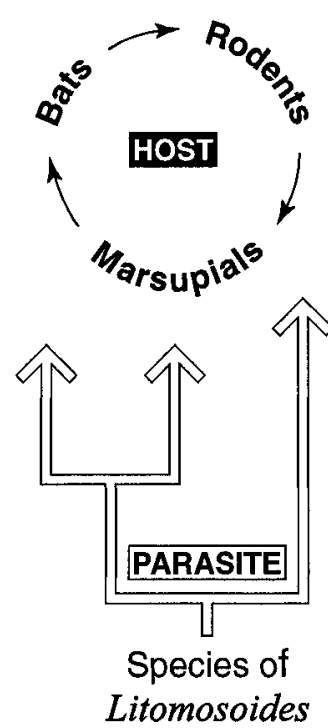

Figure 1. A. Possible model of strict cospeciation between Litomosoides species and their mammalian hosts in the Nearctic and Neotropical regions. This model implies that marsupials carried the ancestral lineage of Litomosoides, bats, and rodents following as more derived clades. As a consequence of this model of evolution, parasites of each mammalian order are predicted to form monophyletic groups (triangles) This model also implies the extinction of species of Litomosoides in all other mammalian orders. B. The alternative hypothesis would imply extensive host switching (arrows) between mammalian hosts, favored by close ecological associations. As a consequence, parasites of each mammalian order are not predicted to form monophyletic groups.

\section{MATERIALS AND METHODS}

\section{Parasite collections}

Parasites were isolated from mammals collected primarily in Bolivia (by S.L.G. or S.V.B.) from May through October 1984-1996. Rodents and marsupials were collected using Sherman ${ }^{\circledR i v}$ live traps baited with oatmeal, bananas, sardines, and vanilla, or Macabee ${ }^{\boxplus o p h e r}$ traps. Bats were netted using mist nets set along or across streams, in flyways, and in fields of banana trees. Data on mammals are stored in either the Department of Mammalogy, American Museum of Natural History; the Division of Mammals, the Museum of Southwestern Biology, the University of New Mexico; or the National Museum of Natural History in La Paz, Bolivia.

In southeastern Nebraska, bats of the family Vespertilionidae were also examined for parasites, including Eptesicus fuscus (Beauvois), Nycticeius humeralis (Rafinesque), Myotis keenii (Merriam), Myotis lucifugus (Le Conte), Lasionycteris noctivagans (Le Conte), Lasiurus borealis (Müller), and Lasiurus cinereus (Beauvois). In Nebraska, bats were captured in mist nets set across streams and creeks from June through October 1995-1996.

Parasites were collected following the methods of Gardner (1996). From each host, all helminths found were collected, blood smears were made, samples of heart, liver, and kidney were preserved either in liquid nitrogen and transported back to permanent storage at $-80 \mathrm{C}$ or were frozen immediately at $-80 \mathrm{C}$. Skins and skeletons were prepared using standard procedures (Yates et al., 1996).

Adult filarioid nematodes isolated from the abdominal or thoracic regions of freshly killed hosts were fixed in glacial acetic acid and stored in $10 \%$ formalin or $70 \%$ ethanol. For study, nematodes were cleared gradually by evaporation of a $70 \%$ ethanol, $2 \%$ glycerol, and
2\% lactic acid solution over a period of 5-7 days (Brant and Gardner, 1997).

To develop the character matrix for a phylogenetic analysis, quantitative and qualitative data were recorded using a calibrated ocular micrometer on a Zeiss Ultraphot microscope. Video images were captured and measured with a computer-aided image measurement system (Jandel JAVA (iw).

\section{Phylogenetic analysis}

We analyzed characters that traditionally are used to diagnose species of Litomosoides. Twenty-four taxa were included in the analysis (Tables I, II) of which the following 9 were identified from our field collection and used to verify the published descriptions: Litomosoides brasiliensis Lins de Almeida, 1936, Litomosoides chandleri Esslinger, 1973, Litomosoides guiterasi (Vigueras, 1934), Litomosoides ctenomyos Brant and Gardner, 1997, Litomosoides esslingeri (Esslinger, 1973), Litomosoides andersoni Brant and Gardner, 1997, Litomosoides thomomydis Gardner and Schmidt, 1986, Litomosoides westi Gardner and Schmidt, 1986. Character states for Litomosa americana were taken from specimens collected from $N$. humeralis in eastern Nebraska and character states for the remaining outgroups were taken from the literature (Boulenger, 1924; Vaz, 1934; Bain and Hocquet, 1968; Petit, 1980).

The morphological character states for the remaining 15 taxa were taken from the following references: Chandler, 1931; Sandground, 1934; Chitwood, 1938; Caballero and Caballero, 1939, 1944, 1947; Bain and Durette-Desset, 1973; Esslinger, 1973; Forrester and Kinsella, 1973; Padilha and de Faria, 1977; Bain et al., 1980, 1982, 1989; Muller, 1980; Gardner and Schmidt, 1986; Brant and Gardner, 1997; de Moraes Neto et al., 1997. Litomosoides sp. Chitwood, 1938, Litomosoides circularis Linstow, 1899, Litomosoides fosteri Caballero and Caballero, 1947, Litomosoides leonilavazquezae Caballero and Caballero, 1939, Litomosoides hamletti Sandground, 1934, Litomosoides patersoni Mazza, 1928, Litomosoides silvai Padilha and de Faria, 1977, and Litomosoides artibei Esslinger, 1973 were omitted from the phylogenetic analysis because of inadequate species descriptions. Litomosoides caliensis Esslinger, 1973 and Litomosoides colombiensis Esslinger, 1973 were omitted also as they were described only from microfilariae.

Lack of an explicit hypothesis of relationships for species of Litomosoides has left the choice of outgroups unclear; however, Bain et al. $(1980,1982,1989,1991)$ and Xie et al. (1994) suggested that the nearest relatives of the genus Litomosoides could be the genera Acanthocheilonema Cobbold, 1870 (parasites of insectivores, nearctic carnivores, pinnipeds, and some rodents), Ackertia (Chabaud and Anderson, 1959) (parasites of South American rodents), and Litomosa (parasites of World bats). For our analysis, 4 species from these 3 genera were used as outgroups, including: Acanthocheilonema evansi Boulenger, 1924, Ackertia dorsti Bain and Hocquet, 1968, L. americana, and Litomosa hugoti Petit, 1980.

A matrix representing 22 morphological characters (Table II) was used for the phylogenetic analysis. Characters were treated as unordered and were initially unweighted and coded as either binary or multistate. Character states were either scored 0 if the state occurred in the outgroup or scored as the alternatives 1 and 2. Character states found to be unclear in the literature were scored as ambiguous (?). The data matrix was analyzed using PAUP 3.1.1 (Swofford, 1993) and the character state distributions were investigated using MacClade version 3.01 (Maddison and Maddison, 1992). Heuristic searches in PAUP were performed using the following options: stepwise addition, addition sequence random with 1,000 repetitions, TBR, MULPARS holding 1 tree at each step, and character state optimization ACCTRAN.

\section{RESULTS}

\section{Character analysis}

From adult filarioid nematodes, 22 morphological characters were coded and are listed below in the order that they appear in the character matrix (Fig. 4; Table II):

1. Shape of head $(0=$ blunt [Fig. $4 A] ; 1=$ attenuated [Fig. 4B]).

2. Symmetry of arrangement of cephalic papillae $(0=$ sym- 


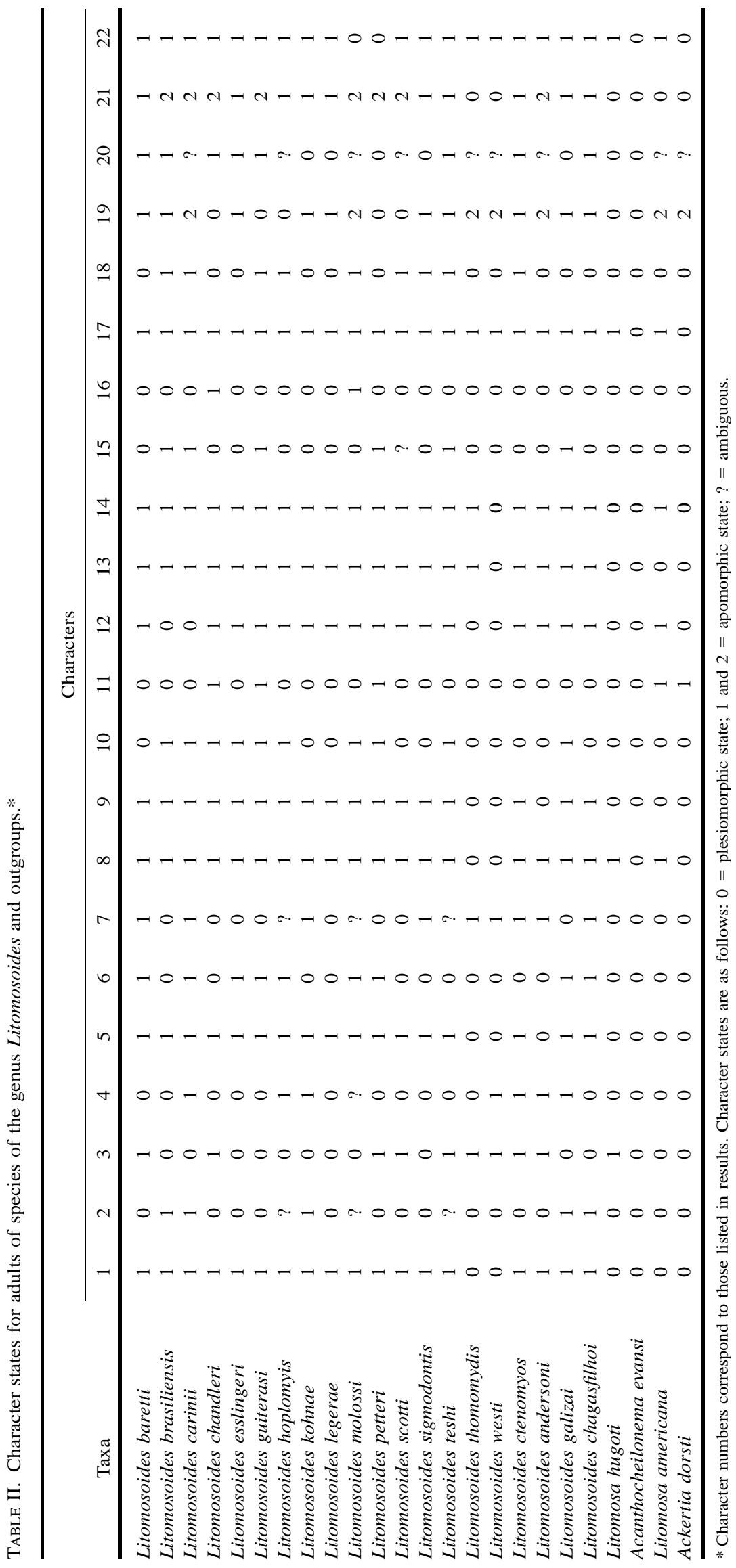


TABLE III. List of each character and the corresponding consistency index (CI) after reweighting of characters from the original set of 20 most parsimonious trees.

\begin{tabular}{rlc}
\hline & \multicolumn{1}{c}{ Character } & CI \\
\hline 1. & Shape of the head & 1.000 \\
2. & Symmetry of cephalic papillae & 0.333 \\
3. & Lateral cephalic papillae & 0.250 \\
4. & Circumstomal papillae & 0.143 \\
5. & Shape of buccal capsule & 1.000 \\
6. & Cuticularization of buccal capsule & 0.200 \\
7. & Segments of buccal capsule & 0.143 \\
8. & Buccal capsule in esophagus & 0.500 \\
9. & Walls of buccal capsule & 1.000 \\
10. & Esophagus & 0.250 \\
11. & Position of vulva & 0.250 \\
12. & Shape of ovijector & 0.333 \\
13. & Shape of female tail & 1.000 \\
14. & Tail digits of female & 1.000 \\
15. & Ovaries in tail & 0.200 \\
16. & Cuticular tubercles on female tail & 0.500 \\
17. & Precloacal papillae on male & 1.000 \\
18. & Pericloacal papillae & 0.200 \\
19. & Number of postcloacal papillae & 0.333 \\
20. & Arrangement of postcloacal papillae & 0.500 \\
21. & Type of right and left spicule & 1.000 \\
22. & Total length ratio of right and left spicule & 0.333 \\
\hline
\end{tabular}

metrical [Fig. 4C]; $1=$ asymmetrical [Fig. 4D]). Symmetrical arrangement of these papillae is considered ancestral (Anderson, 1968). The evolutionary trend suggested by many studies indicates a general reduction and fusing of cephalic papillae, with posterior migration of the remaining papillae, and asymmetrical arrangement, as noted in more derived forms (Anderson, 1968; Chitwood and Chitwood, 1974; Anderson and Bain, 1976; Willmott, 1981).

3. Cephalic papillae $(0=$ present [Fig. $4 \mathrm{C}$ ]; $1=$ reduced [Fig. 4E]). These papillae are well developed along the sides of the cephalic region in ancestral nematodes (Anderson, 1968).

4. Externolateral papillae $(0=4$ [Fig. $4 \mathrm{E}$ ]; $1=$ less than 4 [Fig. 4D]). These papillae occur in variable numbers forming a ring around the mouth.

5. Shape of stoma in longitudinal section $(0=$ triangular [Fig. 4A]; 1 = cylindrical [Fig. 4F]). A cylindrical stoma has long, cuticularized walls. A triangular stoma has its apex directed anteriad.

6. Relative thickness of stoma wall $(0=$ wall robust, thick [Fig. 4F]; $1=$ wall thin [Fig. 4G])

7. Segments of stoma $(0=$ present [Fig. $4 \mathrm{H}] ; 1=$ fused [Fig. 4F]). The segments of the stoma resemble the stoma segments of rhabditoid nematodes considered an ancestral group from which most of the present nematodes have diverged (Chitwood and Chitwood, 1974).

8. Stoma in esophagus $(0=$ embedded [Fig. $4 \mathrm{~A}] ; 1=$ partially embedded [Fig. 4F]). In some of the taxa the stoma is enclosed completely by the esophagus.

9. Outer wall surface of the stoma $(0=$ outer walls smooth [Fig. 4B]; 1 = outer walls thickened irregularly [Fig. 4F]).
In the ingroup, the stoma walls are smooth or have several constrictions, appearing bumpy.

10. Esophagus $(0=$ muscular; $1=$ muscular/glandular $)$. A fully muscular esophagus is considered ancestral (Bain et al., 1982). The derived condition exhibits a muscular portion of the esophagus that gradually changes to glandular toward the esophageal-intestinal junction.

11. Position of vulva $(0=$ posterior to esophageal-intestinal junction; 1 = in region of esophagus). The anteriad migration of the vulva toward the oral opening is considered a derived trait in the tissue-dwelling filarioid nematodes (Vaz, 1934; Bain and Durette-Desset, 1973).

12. Shape of ovijector $(0=$ with median constriction; $1=$ rounded and muscular, no constriction) (Gardner and Schmidt, 1986; Brant and Gardner, 1997).

13. Shape of female tail $(0=$ blunt [Fig. $4 \mathrm{I}] ; 1=$ attenuated [Fig. 4J]).

14. Female caudal lappets $(0=$ present $[$ Fig. $4 \mathrm{I}] ; 1=$ absent [Fig. 4J]). Tail digits are finger-like projections on the terminus of the tail.

15. Ovaries extending into the tail $(0=$ absent; $1=$ present $)$.

16. Cuticular tubercles on female tail $(0=$ absent; $1=$ present). Minute tubercles found on cuticle of the distal portion of the female tail (Esslinger, 1973).

17. Precloacal papillae $(0=$ present; $1=$ reduced [Fig. $4 \mathrm{~K}])$. These papillae occur anterior to the cloaca in males. The basic number of caudal papillae in secernentean nematodes is 10 pairs plus an unpaired precloacal papilla (Bain and Durette-Desset, 1973; Chabaud and Bain, 1994).

18. Pericloacal papillae $(0=$ present [Fig. $4 \mathrm{~K}$ ]; $1=$ absent $)$. These papillae occur in the immediate area of the cloaca in males. Possession of numerous papillae is considered ancestral (Bain and Durette-Desset, 1973; Chabaud and Bain, 1994).

19. Number of postcloacal papillae $(0=8$ [Fig. $4 \mathrm{~L}] ; 1=9-$ $12 ; 2=$ none [Fig. 4O]). The presence of 4 pairs of postcloacal papillae in males is considered ancestral (Bain and Durette-Desset, 1973; Chabaud and Bain, 1994).

20. Arrangement of postcloacal papillae on male tail $(0=$ asymmetrical [Fig. 4M]; $1=$ symmetrical [Fig. 4L]; $2=$ no papillae [Fig. 4O]). If the arrangement of these papillae on the ventral side of the male was symmetrical, then papillae were arranged in pairs rather than randomly. Taxa that do not possess papillae were scored as ambiguous.

21. Shape of right and left spicules $(0=$ outgroup state; $1=$ sigmodontis-type [Fig. 4N]; 2 = carinii-type [Fig. 4O]). This character has been studied and described extensively (see Bain et al., 1989; Brant and Gardner, 1997). The outgroup state was any description of a spicule that could not be placed in either the sigmodontis- or the carinii-type. The carinii-type (e.g., Litomosoides carinii and Litomosoides scotti) is described by Bain et al. (1989: 285) translated as: "The right spicule is sclerified to the distal extreme with a subterminal flange well marked on the dorsal side that may define a terminal hood (e.g., L. carinii); the talon is robust. The blade of the left spicule is composed of a simple, well sclerified portion; the handle is very membranous and is not well defined in L. scotti. The blade is shorter than the handle." The sigmodontis-type (e.g., Litomosoides sigmodontis) is described by Bain et al. 
(1989: 285) translated as: "The right spicule is poorly sclerified as the distal region is slender and tapering sustained by two fine cuticular borders ending in one short membranous partition that has generally a dorsal coil upon the spicule; frequently, the talon does not form a well defined flange or sclerified apical hood, and is shorter and narrower than the carinii type. The blade of the left spicule has a sclerified axis that is longer than the handle; the anterior half of the handle is bordered by large, membranous, longitudinally pleating alae that are visible without dissection."

22. Ratio of Length of right spicule to left spicule $(0=1.0-$ $2.5 ; 1=3.0-7.0)$. In the specimens examined, as well as in the literature, there was a consistent gap between ratios of 2.5 and 3.0.

\section{PHYLOGENETIC ANALYSIS}

The cladistic analysis produced 20 most parsimonious trees, length $=67$, consistency index $(\mathrm{CI})=0.3582$ (Kluge and Far- ris, 1969). The strict consensus tree is shown in Figure 2. As defined, species assigned to Litomosoides do not form a monophyletic group because 2 of the ingroup taxa (L. thomomydis and L. westi) are grouped with the outgroup. Characters 1 (shape of the head), 5 (shape of the stoma), 9 (walls of the stoma), and 17 (precloacal papillae on male) are uniquely derived and unreversed ( $\mathrm{CI}=1$ in all 20 trees). Branch A, supporting the ingroup (except $L$. thomomydis and $L$. westi) is defined by 5 characters of which only character 1 (shape of the head) is uniquely derived and unreversed. Characters 5 (shape of the stoma) and 9 (walls of stoma) support branch B that separates $L$. andersoni from the rest of the species in the genus.

Because of the amount of homoplasy present in the data set, characters were reweighted a posteriori using the maximum value of the rescaled CI for each character (Farris, 1969). Reweighting of the characters enabled us to assess the strength of each character and compare the resulting tree to the original 20 most parsimonious trees. This procedure resulted in a single tree with length $=15.34, \mathrm{CI}=0.67$ that was different from the

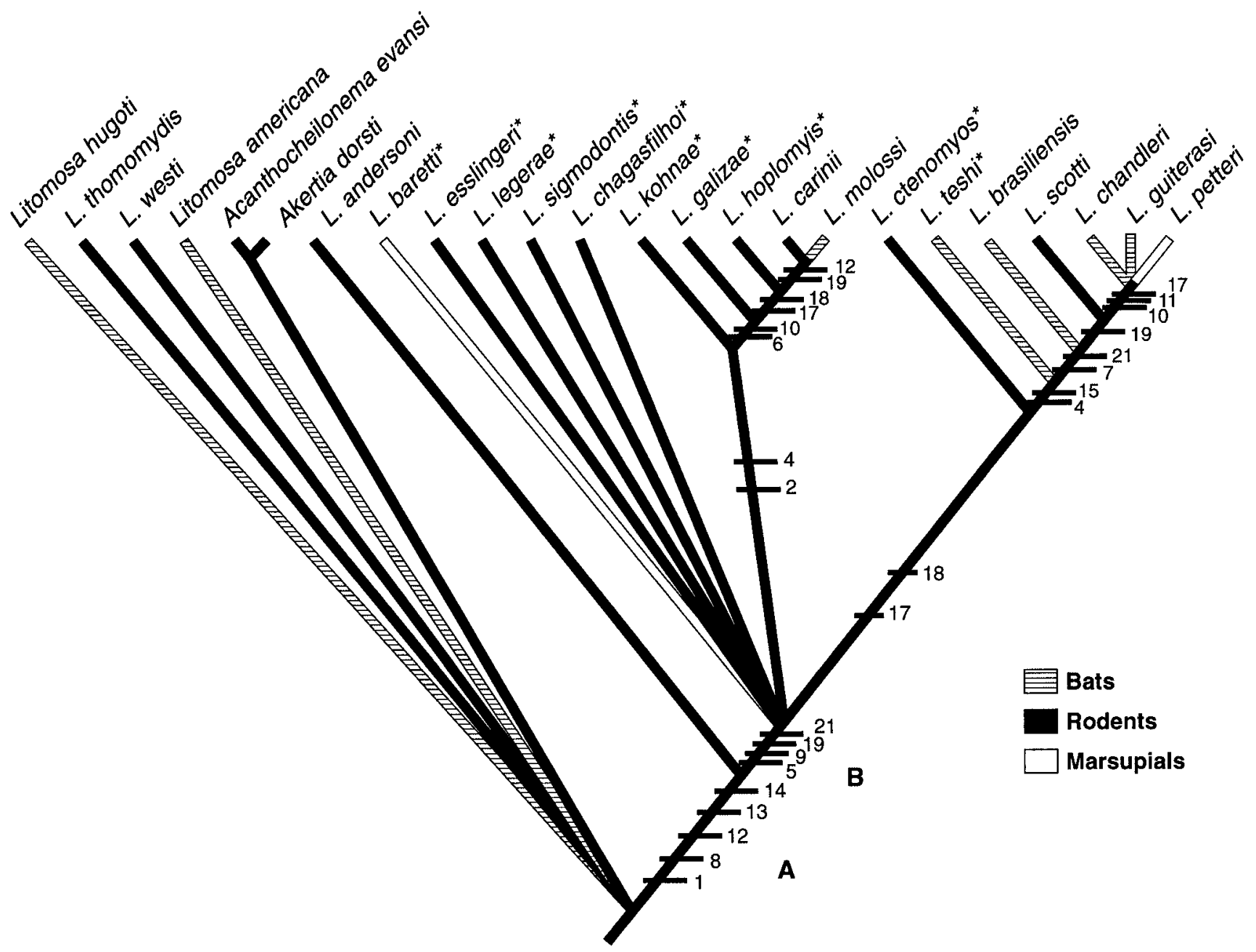

FIGURE 2. The strict consensus tree of the 20 most parsimonious trees, length $=67$, generated from the cladistic analysis of the adult character data matrix presented in Table II. Species of Litomosoides are preceded by L. Characters are indicated following a dash and bolded number and unique shared derived characters are outlined. Letters correspond to clades discussed in the text. An asterisk denotes species of Litomosoides with the sigmodontis-type of spicule. Indicated by branch shading, the host group is mapped onto the cladogram for each species of Litomosoides. See Table I for the host group and distribution for each species of Litomosoides. 


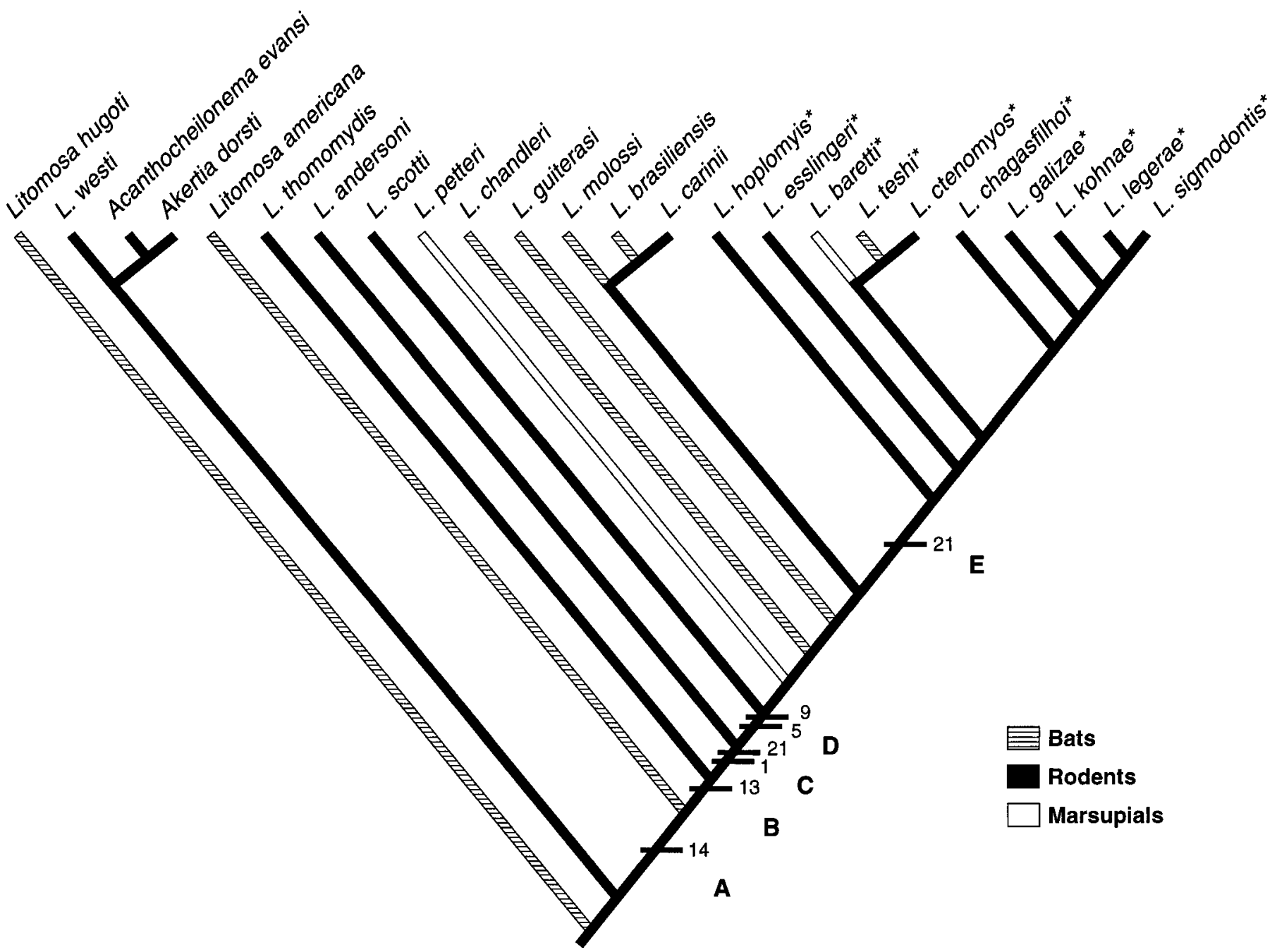

FIGURE 3. The reweighted tree obtained by successive approximations, starting with the 20 parsimonious trees (length $=15.4$ ), generated from analysis of the adult characters listed in Tables II and III. Characters are indicated following a dash; numbers and letters correspond to the characters in the results section. An asterisk denotes species of Litomosoides with the sigmodontis-type of spicule. Indicated by branch shading, the host group is mapped onto the cladogram for each species of Litomosoides.

original set of 20 trees (Fig. 3). However, in agreement with the set of 20 most parsimonious trees, the reweighted tree also fails to support Litomosoides and Litomosa as monophyletic groups.

In Table III, characters $1,5,9,13,14,17$, and 21 have a reweighted $\mathrm{CI}=1$ that support the following groups in Figure 3: Branch A, character 14 (tail digits of female) supports the ingroup taxa excluding $L$. westi but including $L$. americana. Branch B, supported by character 13 (shape of female tail), excludes $L$. americana, grouping the remaining ingroup taxa. Branch C, supported by characters 1 (shape of the head) and 21 (type of right and left spicule), placed L. thomomydis as the sister group to the rest of species of Litomosoides. Litomosoides thomomydis is basal in both the reweighted tree and the strict consensus tree. Supported by characters 5 (shape of the stoma) and 9 (walls of stoma), branch D is the single branch uniting the same taxa as the strict consensus tree (Fig. 2, branch B). Finally, branch E, supported by character 21 (type of right and left spicules), defines a clade that corresponds to the sigmodon- tis-type of spicules. The carinii-type of spicules is ancestral in both the strict consensus and the reweighted trees. The reweighted tree partially resolves the polytomy in the outgroup present in the strict consensus tree; $L$. westi is united by character 8 (stoma in esophagus) with $A$. evansi and $A$. dorsti; and both species of Litomosa fail to form a monophyletic group in this tree and in the strict consensus tree (Figs. 2, 3).

To test the null hypothesis of a host-parasite coevolution, a constraint tree was created that forced the ingroup taxa to group according to their host affiliation such that all nematodes parasitizing each group (order) of mammals form a monophyletic group (Fig. 1A). Enforcing this constraint on the original data set resulted in 102 equally parsimonious trees, length $=80$, CI $=0.30$ (trees not shown). Using the Templeton test (Templeton, 1983), parsimony scores of these 102 trees were compared to the original 20 trees, length $=67$ (13 steps shorter). All constraint trees were significantly worse $(P<0.05)$ than the 20 most parsimonious trees. Enforcing the host constraint on the reweighted data-set resulted in 150 equally parsimonious trees, 


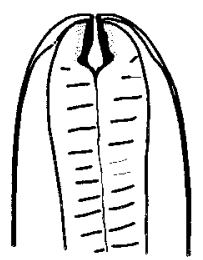

A
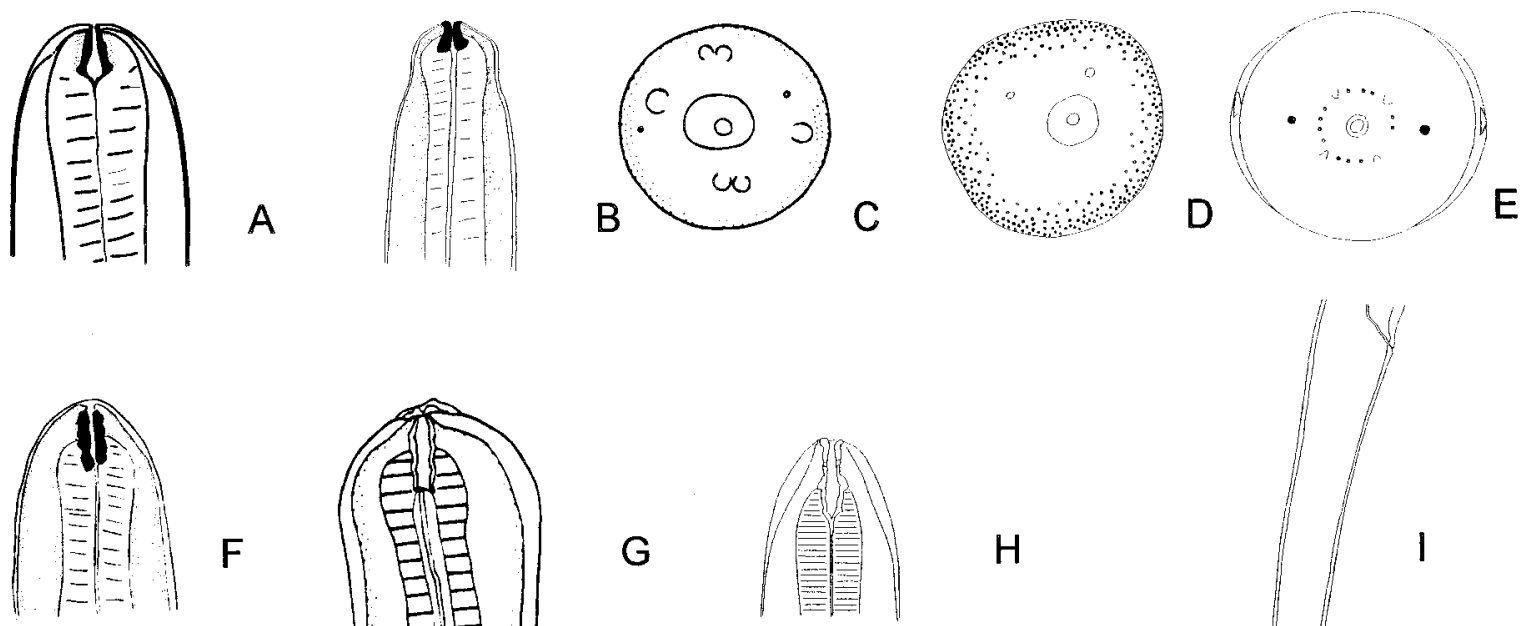

$\mathrm{F}$
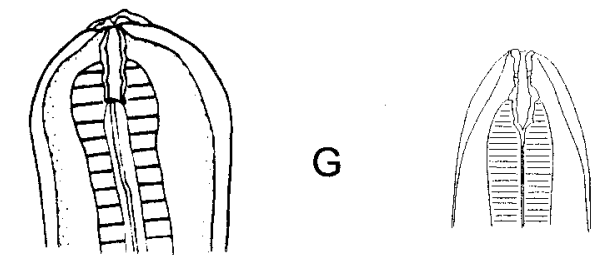

$\mathrm{H}$
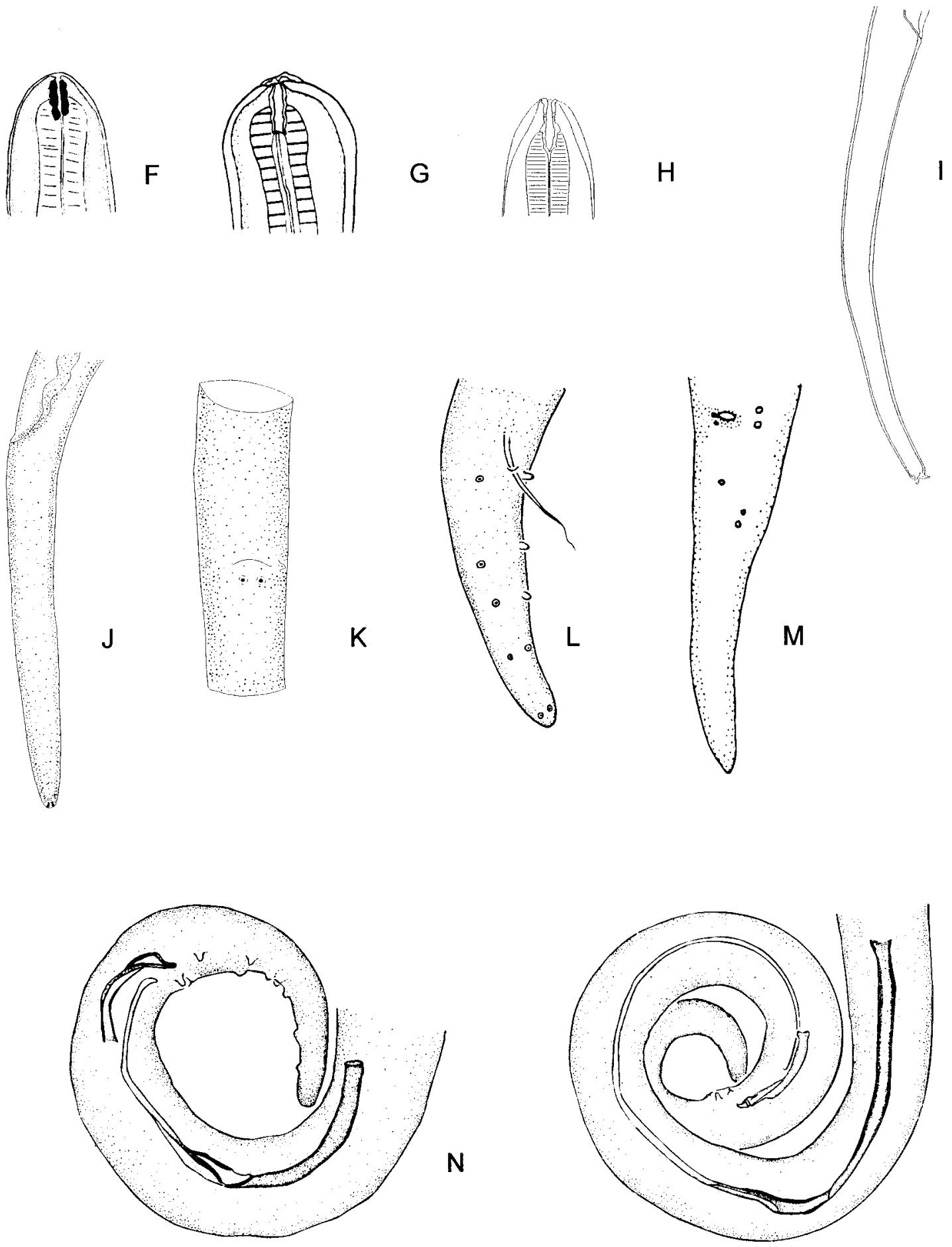

$\mathrm{O}$

Figure 4. Diagrams of some of the characters used in the phylogenetic analysis. Figures B, D, F, J, K, L, N, and O modified from Brant and Gardner (1997). Figure C modified from Forrester and Kinsella (1973). Figure M modified from Bain et al. (1980). Figures A, E, and I adapted from Gardner and Schmidt (1986). Figure H modified from Bain et al. (1980). 
length $=23.4$ (trees not shown). Using the Templeton test, these 150 trees were compared to the reweighted tree (length $=$ 15.36) and all constraint trees were significantly worse $P<0.02$ (trees not shown).

\section{DISCUSSION}

Based on this analysis, we conclude that species of the genus Litomosoides, as defined at present, do not form a monophyletic group. Moreover, reweighting of the characters resulted in a single tree that was significantly worse relative to each of the original 20 most parsimonious trees, indicating character homoplasy. On examination of the characters in Table II and of the character CIs in Table III, these incongruences become evident because there are few synapomorphies (characters 1, 5, 9, and 17) and no single character supports the monophyly of all ingroup taxa.

Six characters contained phylogenetic information and had been considered previously stable by Bain et al. (1989) as diagnostic for species of Litomosoides: shape of spicules (character 21), form of the stoma (characters 5, 9), and presence and disposition of the caudal papillae of the male (characters 17, 19, 20) (Sandground, 1934; Bain et al., 1989). Chitwood and Chitwood (1974) considered the stoma too variable to use as a character for differentiation among filarioid nematodes. Bain et al. (1989) defined 2 groups of Litomosoides that correspond to the structure of both the right and left spicule; sigmodontis-type and carinii-type (character 21). Both of these types of spicules are found in nematodes occurring in marsupials, rodents, and bats with geographic distributions in both North and South America. The strict consensus tree did not show distinct monophyletic groups of either spicule type and did not correspond to host monophyly or to the geographic distributions of the parasites (Fig. 2; Table I). In the tree constructed with character reweighting, all taxa with the sigmodontis-type of spicule were placed in a derived monophyletic group, suggesting that the carinii-type of spicule may be the ancestral condition (Fig. 3, clade E).

Caudal papillae in the males have also been regarded as significant and stable in the evolution and classification of filarioid nematodes. As these nematodes evolved, there was evidently a migration of the anterior precloacal and pericloacal papillae to the postcloacal position (Sandground, 1934; Bain and DuretteDesset, 1973; Esslinger, 1973; Bain, 1981; Bain et al., 1989; Chabaud and Bain, 1994). Our results show that these 2 characters, the arrangement and number of postcloacal papillae (characters 19 and 20), contain little or no phylogenetic information in hypothesizing relationships among Litomosoides.

Bain et al. (1989) considered the structure of the stoma to be the most significant morphological character that can be used to differentiate members of this genus from other members of Onchocercidae and within Litomosoides. In both the unweighted strict consensus tree and the reweighted tree characters 5 and 9 (shape and walls of stoma, respectively) grouped a majority of the ingroup taxa, excluding 3 taxa that are morphologically distinct from other members of Litomosoides (L. andersoni, L. thomomydis, and L. westi). Our analysis supports the assertion of Bain et al. (1989). The incompatibility of the set of 20 most parsimonious trees and the reweighted tree suggests that most of the characters presently used for species di- agnosis lack much phylogenetic information. Not all characters are of equal value in elucidating relationships among taxa, and the decision of what characters to emphasize and the weight given to these characters is subject to debate (Goloboff, 1993).

Litomosoides thomomydis and L. westi (both parasites of rodents of the family Geomyidae in Central North America) share morphological similarities (spicules and stoma) with the genus Litomosa (Bain et al., 1989), but they did not group with either L. hugoti (Old World distribution in bats) or L. americana (Nearctic distribution in 1 species of bat). Our results indicate (as suggested by Bain et al. [1989]) that L. thomomydis and L. westi do not belong to the genus Litomosoides. In addition, parasite taxa found in marsupials were not basal clades, indicating they were not the ancestral hosts of Litomosoides. Furthermore, Litomosoides baretti and Litomosoides petteri, both found in the marsupial Marmosa cinerea in Brazil, were not sister species and were placed in distant positions on the consensus tree (Figs. 2 and 3). The analysis enforcing a topological host constraint, supporting the monophyly of parasites of marsupials, rodents, and bats, yielded significantly longer trees indicating that host switching was the primary mode of evolution in species of the genus Litomosoides (Fig. 1B).

Bain et al. (1991) postulated that Litomosoides were fundamentally parasites of South American bats that switched subsequently into rodents. On the strict consensus tree, the host of the basal taxon, L. andersoni, is an hystricognath rodent, suggesting that these nematodes may have originated at an early stage in the evolution of this host group and then diversified subsequently in bats (Figs. 2, 3). Additionally, our results show the most basal taxa on the tree are found in rodents and a marsupial and not in bats.

Species included presently in Litomosoides do not comprise a monophyletic group, and our analysis does not support either of the above hypotheses. However, within a phylogenetic framework, our results agree with the assertions of Bain et al. (1989) indicating that host switching is the primary process that shaped the current patterns of distribution of species of the genus Litomosoides among New World mammals (Fig. 1B) but disagree with the host of origin as a bat. Knowledge of the appropriate intermediate host species for each species of Litomosoides is probably critical to evaluate further the mode of evolution shaping this host-parasite association.

Our results are the first attempt at reconstructing the phylogenetic relationships among the species of Litomosoides. The paucity of morphological characters in this group and the extent of homoplasy evident from the analysis indicates that robust phylogenetic analyses depending only on morphology will be difficult. Future efforts in the direction of developing biological databases of DNA sequences should improve our resolution and ability to provide a more accurate history of the relationships between these filarioid nematodes and their hosts.

\section{ACKNOWLEDGMENTS}

The work was supported by the National Science Foundation (grant BSR-8612329 to S.L.G., D. W. Duszynski, and T. L. Yates, BSR-9024816, and DEB-9496263 to S.L.G., BSR8408923 to T. L. Yates, and BSR-8316740 to S. Anderson). Additional support was provided directly by the American $\mathrm{Mu}-$ seum of Natural History, The Museum of Southwestern Biol- 
ogy, and the Tinker Foundation. The following organizations provided either specimens or logistic support in the field: El Museo National de Historia Natural, La Paz; The Museum of Southwestern Biology, The University of New Mexico; and El Instituto Boliviano de Biologia de la Altura, La Paz, Bolivia. Identification of mammals was assisted by Sydney Anderson, American Museum of Natural History, New York and by Terry L. Yates, Museum of Southwestern Biology, Department of Biology, The University of New Mexico. We also thank Odile Bain, and the rest of our colleagues at the National Museum of Natural History in Paris for assistance and encouragement during the past 2 decades. Special thanks are extended to Guillermo Ortí for his invaluable assistance in the phylogenetic analyses and to Russel Benedict for his help in netting bats in $\mathrm{Ne}$ braska.

\section{LITERATURE CITED}

ANDERSON, R. C. 1968. The comparative morphology of cephalic structures in the superfamily Filarioidea (Nematoda). Canadian Journal of Zoology 46: 181-199.

, AND O. BAIN. 1976. Keys to genera of the order Spirurida. Part 3: Diplotriaenoidea, Aproctoidea, and Filarioidea. In CIH keys to the nematode parasites of vertebrates, R. C. Anderson, A. G. Chabaud, and S. Willmott (eds.). Commonwealth Agricultural Bureaux, Farnham Royal, U.K., p. 59-116.

BAIN, O. 1981. Filariids and their evolution. Parasitology 82: 161-174. , M. BAKer, AND A. G. Chabaud. 1982. Nouvelles données sur la lignée Dipetalonema (Filarioidea, Nematoda). Annales de Parasitologie 57: 593-620.

- AND M. C. Durette-Desset. 1973. Cycle de Skrjabinofilaria skrjabini, filaire de marsupial sud-américain: Position systématique. Annales de Parasitologie 48: 61-79.

$\longrightarrow$, AND P. HocQueT. 1968. Akertia dorsti n. sp. Parasite de la viscache Lagidum peruanum. Bulletin du Múseum National d'Histoire Naturelle, 2 ser. 40: 399-402.

$\longrightarrow$, G. Petit, and S. Berteaux. 1980. Description de deux nouvelles Filaires du genre Litomosoides et de leurs stades infestants. Annales de Parasitologie Humaine et Comparée 55: 225-237.

$\longrightarrow, \longrightarrow$ AND M. Diagne. 1989. Étude de quelques Litomosoides Parasites de Rongeurs; Conséquences Taxonomiques. Annales de Parasitologie Humaine et Comparée 64: 268-289.

, M. Philipp, H. Hoste, And P. Yvore. 1991. Animal models in the study of the phenomenon of parasitism: Filariae and other parasites. Annales de Parasitologie Humaine et Comparée 66: 64-68.

Boulenger, C. L. 1924. The filariid of the camel, Acanthocheilonema evansi (Lewis). Parasitology 4: 419-423.

Brant, S. V., AND S. L. GARDNER. 1997. Two new species of Litomosoides (Nemata: Onchocercidae) from Ctenomys opimus (Rodentia: Ctenomyidae) on the altiplano of Bolivia. Journal of Parasitology 83: 700-705.

BRooks, D. R. 1985. Historical ecology: A new approach to studying the evolution of ecological association. Annals of the Missouri Botanical Garden 72: 660-680.

- AND D. A. MCLenNAN. 1991. Phylogeny, ecology, and behavior: A research program in comparative biology. The University of Chicago Press, Chicago, Illinois, 434 p.

$\longrightarrow$, and 1 1993. Parascript: Parasites and the language of evolution. Smithsonian Institution Press, Washington, $429 \mathrm{p}$.

Caballero, E., and C. Caballero. 1939. A new filariid worm from Mexican bats. Transactions of the American Microscopical Society 58: $456-458$.

— AND — 1944. Una nueva especie del genero Litomosoides y consideraciones acerca de los caracteres sistematicos de las especies de este genero. Anales del Instituto de Biologia Universidad Nacional Autonoma, de Mexico 15: 383-388.

, AND - 1947. Algunas filarias de mammiferos y de reptiles de las republicas de Colombia y Panamá. Anales del Instituto de Biologia Universidad Nacional Autonoma, de Mexico 18: 169188.
Chabaud, A. G., And O. Bain. 1994. The evolutionary expansion of the Spirurida. International Journal for Parasitology 24: 11791201.

Chandler, A. 1931. New genera and species of nematode worms. Proceedings of the U.S. National Museum 78: 1-11.

Chitwood, B. G. 1938. IV. Some nematodes form the caves of Yucatan. Carnegie Institution of Washington, Publication No. 491: 51-66.

—, AND M. B. ChITwOOD. 1974. Introduction to nematology. University Park Press, International Publishers in Science and Medicine, Chamber of Commerce Building, Baltimore, Maryland, $334 \mathrm{p}$.

EssLinger, J. H. 1973. The genus Litomosoides Chandler, 1931 (Filarioidea: Onchocercidae) in Colombian bats and rats. Journal of Parasitology 59: 225-246.

FARRIS, J. S. 1969. Successive approximations approach to character weighting. Systematic Zoology 18: 374-385.

ForRester, D. J., AND J. M. Kinsella. 1973. Comparative morphology and ecology of two species of Litomosoides (Nematoda: Filarioidea) of rodents in Florida, with a key to the species of Litomosoides Chandler, 1931. International Journal for Parasitology 3: 255-263.

GARDNER, S. L. 1996. Appendix 6: Field parasitology techniques for use with mammals. In Measuring and monitoring biological diversity: Standard methods for mammals, D. E. Wilson, F. R. Cole, J. D. Nichols, R. Rudran, and M. S. Foster (eds.). Smithsonian Institution Press, Washington, D.C., p. 291-298.

Gardner, S. L., and G. D. Schmidt. 1986. Two new species of Litomosoides (Nematoda: Onchocercidae) from pocket gophers (Rodentia: Geomyidae) in Colorado. Systematic Parasitology 8: 235242.

GolobofF, P. A. 1993. Parsimony and weighting: A reply to Turner and Zandee. Cladistics 11: 91-104.

Huelsenbeck, J. P., and B. Rannala. 1997. Phylogenetic methods come of age: Testing hypotheses in an evolutionary context. Science 276: 227-232.

Kluge, A. G., AND J. S. Farris. 1969. Quantitative phyletics and the evolution of anurans. Systematic Zoology 18: 1-32.

MadDison, W. P., AND D. R. MADDISON. 1992. MacClade: Analysis of phylogenetic and character evolution, version 3.01. Sinauer Associates, Inc., Sunderland, Massachusetts, 398 p.

Moraes Neto, A. H. A. de, R. M. Lanfredi, AND W. De Souza. 1997. Litomosoides chagasfilhoi sp. nov. (Nematoda: Filarioidea) parasitizing the abdominal cavity of Akodon cursor (Winge, 1887) (Rodentia: Muridae) from Brazil. Parasitology Research 83: 137-143.

Muller, R. 1980. Litomosoides barretti n. sp. from the Ashy Opossum in Brazil (Nematoda, Filarioidea). Revista Brazileira de Biologia 40: $81-83$.

Padilha, T. N., AND M. J. DE Faria. 1977. Litomosoides silvai n. sp. proveniente de rato do mato, Akodon arviculoides (Wagner) (Nematoda, Filarioidea). Revista Brasileira de Biologia 37: 535-537.

PetiT, G. 1980. Sur les Filarires du genre Litomosa (Nematoda, Filarioidea), parasites de Chauves-soires. Bulletin du Múseum National d'Histoire Naturelle, 4 ser. 2: 365-374.

SANDGROUND, J. H. 1934. On a species of the filariid genus Litomosoides. Annals and Magazine of Natural History XIV: 595-599.

SwOFFORD, D. L. 1993. PAUP: Phylogenetic analysis using parsimony, version 3.1. Center for Biodiversity Illinois Natural History Survey, Champaign, Illinois, $257 \mathrm{p}$.

Templeton, A. R. 1983. Phylogenetic inference from restriction endonuclease site maps with particular reference to the humans and apes. Evolution 37: 221-244.

VAZ, Z. 1934. Ackertia gen. nov. for Litomosa burgosi De La Barrera, 1926 , with notes on the synonymy and morphological variations of Litomosoides carinii (Travassos, 1919). Annals of Tropical Medicine and Parasitology 28: 143-149.

Willmott, S. M. 1981. Evolution of helminths. Parasitology 82: 161174.

Xie, H., O. Bain, And S. A. Williams. 1994. Molecular phylogenetic studies on filarial parasites based on 5 s ribosomal spacer sequences. Parasite 1: 141-151.

YATES, T. L., C. JoNES, AND J. A. CoOK. 1996. Appendix 3: Preservation of voucher specimens. In Measuring and monitoring biological diversity: Standard methods for mammals, D. E. Wilson, F. R. Cole, J. D. Nichols, R. Rudran, and M. S. Foster (eds.). Smithsonian Institution Press, Washington, D.C., p. 265-273. 


\section{ANNOUNCEMENT . . .}

VIII European Multicolloquium of Parasitology will meet in Poznan, Poland, 10-14 September 2000. For information contact: Organizing Committee, Department of Biology and Medical Parasitology, Karol
Marcinkowski University of Medical Sciences, Fredry Street 10, 61701 Poznan, Poland. Telephone: (48-61) 852-71-92. Fax: (48-61) 852-

71-92. email: emop8@eucalyptus.usoms.poznan.pl 